\title{
GRUPOS ECONÔMICOS EVASIVOS NO CONTEXTO DO FEDERALISMO FISCAL BRASILEIRO
}

IÚRI SILVA

Mestrando em Direito Político e Econômico (Mackenzie). Especialista em Direito Tributário. Professor de Direito (Universidade de Mogi das Cruzes). Procurador da Fazenda Nacional. Email:iuridaniel84@gmail.com.

PALAVRAS-CHAVE: Sonegação; Federalismo Fiscal Brasileiro; Police Maker; Police Decision Maker; Grupo Econômico de Fato.

\section{INTRODUÇÃO}

A sonegação fiscal subtrai do financiamento dos direitos fundamentais expressiva quantia em cada exercício financeiro.

Segundos dados fornecidos no domínio eletrônico "Quanto custa o Brasil?"1, somente no ano de 2018, entre 01 de janeiro de 2018 a 18 de setembro de 2018, estima-se que a quantia de $R \$$ 408.638.345.761,08 (quatrocentos e oito bilhões, seiscentos e trinta e oito milhões, trezentos e quarenta e cinco mil, setecentos e sessenta e um Reais e oito centavos) deixou de ser recolhida ao erário, em razão de práticas evasivas.

\footnotetext{
${ }^{1}$ O domínio é organizado pelo Sindicado dos Procuradores da Fazenda Nacional e pode ser acessado através do link http://www.quantocustaobrasil.com.br/.
} 


\section{Personalidade Acadêmica Homenageada: \\ Florisbal de Souza Del'OImo (Professor Convidado - UNICURITIBA)}

A evasão fiscal afeta sensivelmente os direitos fundamentais, considerando o substrato econômico que permeia a efetivação de políticas públicas. Com efeito, os direitos são financiados pelos recursos ${ }^{2}$ arrecadados pelo Estado Fiscal $^{3}$.

Tratando-se de fenômeno inserido no gênero corrupção, a evasão fiscal afeta os mais básicos direitos, obliterando o futuro dos menos favorecidos, mediante a subtração da prestação de direitos essenciais, tais como a saúde e a educação.

Em outro prisma, a sonegação desequilibra a ordem econômica, eliminando do mercado - em razão da prática predatória de preços subsidiada pelo odioso "lucro" do ilícito tributário - as empresas que regularmente adimplem as obrigações tributárias. Por outro lado, desestimula o pagamento regular e voluntário de tributos, em detrimento do sistema de deveres fundamentais que alicerça os direitos respectivos. De fato, o dever jurídico fundamental de pagar tributos - baldrame financeiro que sustenta a dignidade da pessoa humana - é afrontado pela prática contumaz de evasão.

O tema da sonegação fiscal ganha ainda mais relevo no caso brasileiro, em razão de dois aspectos que precisam ser considerados.

Primeiramente, percebe-se que a forma tem sido utilizada para escamotear intenções evasivas. Com efeito, foram vários os casos reconhecidos pelos Tribunais pátrios e pela Administração Tributária em que demonstrada a absoluta divergência entre a forma negocial utilizada para celebração de atos jurídicos e a real intenção evasiva.

$\mathrm{Na}$ corrida para driblar a fiscalização tributária, os institutos jurídicos adquirem contornos jamais pensados pelo legislador ou pelo intérprete. Regime de bens de matrimônio transforma-se em escudo para a prática de simulações e

\footnotetext{
${ }^{2}$ HOLMES, Stephen; SUSTEIN, Cass R. The costs of rights: why liberty depends on taxes. New York: W. W. Norton, 2000.

3 "(...) Pois, sendo o estado fiscal o estado cujas necessidades financeiras são essencialmente cobertas por impostos, facilmente se compreende que ele tem sido (e é) a regra do estado moderno. Todavia, se é certo que este, pela própria natureza da realidade econômica moderna, é necessariamente um estado financeiro - um estado cujas necessidades materiais são cobertas através de meios de pagamento, ou seja, de dinheiro que ele obtém, administra e aplica, e não, salvo em casos muito excepcionais e limitados, através de prestações naturais (prestações em espécie ou de facere) exigidas aos seus cidadãos -, não é menos certo que ele nem sempre se tem apresentado como um estado fiscal, havendo estados que claramente configuraram (ou configuram) verdadeiros estados proprietários, produtores ou empresariais" (NABAIS, 1998, p. 192).
} 


\section{Personalidade Acadêmica Homenageada: \\ Florisbal de Souza Del'OImo (Professor Convidado - UNICURITIBA)}

confusões; usucapiões transformam-se em institutos voltados à fraude à execução; constituição de pessoas jurídicas torna-se instrumento para lavagem de capitais.

O planejamento tributário, concebido para ser instrumento lícito de elisão, pode tornar-se, neste cenário, mecanismo a serviço da sonegação. É evidente que se deve sempre ter o cuidado de diferenciar as condutas a partir da intenção do agente econômico. Por óbvio, o planejamento tributário é um instrumento lícito a serviço do contribuinte. $\mathrm{Na}$ análise de condutas, contudo, deve-se perquirir a real intenção do agente, interpretando-se economicamente os negócios, em busca de aferir a existência de real business purpose. No ponto, direito e economia mais uma vez se entrelaçam ${ }^{4}$, não sendo possível interpretar no vácuo ${ }^{5}$ os institutos jurídicos, a saber, apenas sob a ótica da dogmática analítica. O estudo da sonegação não pode olvidar as valiosas contribuições das ciências sociais que integram a zetética ${ }^{6}$.

O segundo aspecto fundamental que tangencia a compreensão da sonegação fiscal concerne à dimensão territorial brasileira e à forma de Estado para fins de distribuição de poder. É que o controle da sonegação fiscal em um Estado de dimensão territorial continental corresponde à hercúlea tarefa. A dificuldade é agravada pela atuação de entes federativos que ainda pouco dialogam.

Fato é que os grupos econômicos empresariais evasivos - a saber, entes societários constituídos através de compartilhamento de estrutura, esvaziamento patrimonial, confusão e abuso de forma - utilizam o abuso de personalidade para a prática de sonegação fiscal.

Há de se ressaltar que a formação de grupos econômicos não configura per si ato ilícito ou abusivo. Aliás, a formação de grupos econômicos formais é disciplinada pela da Lei ํㅜ 6.404, de 15 de dezembro de 1976. O desvio consiste na composição abusiva de estruturas econômicas voltadas a fim de fraudar credores, notadamente o credor fiscal.

\footnotetext{
${ }^{4}$ Aqui se registrem os estudos da Escola de Chicago acerca da relação em entre direito e economia, estudada através do movimento intitulado Law \& Economics (Posner, 2014). O autor destaca que "economic is a powerful tool for analysing a vast range of legal questions bus that most lawyers and law students (...) have difficulty connecting economic principles to concrete legal problems" (p. 3).

${ }^{5} \mathrm{Em}$ sentido semelhante, especificamente sobre a interpretação analítica dos institutos processuais, Cappelletti registra: "O processo, no entanto, não deveria ser colocado no vácuo. Os juristas precisam, agora, reconhecer que as técnicas processuais servem a funções sociais" (p. 12).

6 FERRAZ JÚNIOR, Tercio Sampaio. A ciência do direito. 14.ed. São Paulo: Atlas, 2014.
} 


\section{Personalidade Acadêmica Homenageada:}

Florisbal de Souza Del'OImo (Professor Convidado - UNICURITIBA)

As estruturas econômicas evasivas espraiam-se por todo território nacional com o escopo de maximização de lucros às custas do dever fundamental de pagamento de tributos. Aproveitam-se do vácuo de poder deixado pelos problemas não solucionados do federalismo fiscal brasileiro ${ }^{7}$. Fixam sedes fictícias em domicílios fiscais cujos impostos possuem alíquotas menores, por exemplo, e utilizam-se das "guerras fiscais" para locupletamento. A tais grupos interessa que os desafios do federalismo fiscal brasileiro permaneçam inatacados.

\section{PROBLEMATIZAÇÃO}

É no contexto do cenário descrito que exsurge o problema a ser tratado por meio da pesquisa ora empreendida, resumido na seguinte indagação: "o federalismo fiscal brasileiro é compatível com um modelo de performance fiscal que coíba repressiva e preventivamente a formação de grupos econômicos voltados à sonegação? Caso a resposta seja afirmativa, como seria possível compatibilizar o federalismo fiscal brasileiro com a necessidade de efetivação do dever jurídico fundamental de pagar tributos diante do contexto narrado"?

\section{METODOLOGIA}

A pesquisa está alicerçada no método lógico-dedutivo e na análise empírica, utilizando-se dados públicos divulgados pela Procuradoria-Geral da Fazenda Nacional, pela Receita Federal do Brasil e pelo Poder Judiciário, notadamente pelo Poder Judiciário Federal.

\footnotetext{
${ }^{7}$ Ferraz Junior e Marco Aurélio Greco (1998) discorrem sobre os desafios do federalismo fiscal solidário ou cooperativo brasileiro. Os autores arrolam cinco desafios, sendo três de ordem política, quais sejam a equalização da carga tributária global; a distribuição de encargos públicos; e a guerra fiscal. São desafios de ordem técnica a definição de critérios claros de competência tributária e a neutralidade da tributação.
} 


\section{Personalidade Acadêmica Homenageada:}

Florisbal de Souza Del'Olmo (Professor Convidado - UNICURITIBA)

\section{REFERENCIAL TEÓRICO}

A pesquisa vale-se dos estudos jurídicos de Casalta Nabais acerca do dever jurídico fundamental de pagar tributos, bem como da análise histórica empreendida por Marta Arretche acerca do federalismo fiscal.

\section{HIPÓTESE}

A priori, não parece haver incompatibilidade entre o federalismo fiscal e a eficiência no controle de atos ilícitos evasivos praticados por grupos econômicos abusivos, desde que modelado o federalismo brasileiro à luz do quanto proposto por Arretche a partir da distinção entre police decision maker e police maker, passando, pois, a UNIÃO a coordenar rede de atuação com a colaboração de Estados e Municípios, respeitando-se o núcleo essencial da autonomia dos entes federativos.

\section{RESULTADOS ESPERADOS}

A partir da coordenação e cooperação dos entes, será possível adotar mecanismos integrados que se voltem à eficiência no combate à evasão. Sendo assim, espera-se, a partir do eixo organizacional proposto por Arretche, propor alternativas que reduzam o vácuo de poder atualmente decorrente dos não solucionados problemas do federalismo fiscal brasileiro.

\section{CONCLUSÃO}

A ordem fiscal hígida deve ser vislumbrada como direito fundamental difuso, tutelável através da construção de políticas públicas planejadas e estruturas em rede. A compreensão do federalismo fiscal e a situação ontológica do problema nos desafios do federalismo são importante aspecto para o entendimento holístico do fenômeno da sonegação fiscal. 
Personalidade Acadêmica Homenageada:

Florisbal de Souza Del'OImo (Professor Convidado - UNICURITIBA)

\section{REFERÊNCIAS}

ARRETCHE, Marta. Democracia, federalismo e centralização no Brasil. Rio de Janeiro: Editora FGV; Editora Fiocruz, 2012.

GRECO, Marco Aurélio. Planejamento tributário. 3.ed. Rio de Janeiro: Dialética, 2011.

, Marco Aurélio. FERRAZ JUNIOR, Tercio Sampaio. Desafios do federalismo fiscal brasileiro. Revista do Instituto dos Advogados de São Paulo, Ano 1, n. 2 Julho-Dezembro de 1998, São Paulo: 1998, pp. 97-104.

MAMEDE, Gladston; MAMEDE, Eduardo Cotta. Holding familiar e suas vantagens: planejamento jurídico e econômico do patrimônio e da sucessão familiar. 9.ed. São Paulo: Atlas, 2017.

NABAIS, José Casalta. O dever fundamental de pagar impostos. Coimbra: Almedina, 1998.

PEIXOTO, Daniel Monteiro. Responsabilidade Tributária e os atos de formação, administração, reorganização e dissolução de sociedades. São Paulo: Saraiva, 2012.

POSNER, Richard. Economic analysis of law. 9.ed. New York: Wolters Kluwer Law \& Business, 2014. 